\title{
Recorrido histórico de la guitarra jazz en Santa Fe
}

\author{
Sus principales actores de 1955 a 2005 \\ Oscar Castellano \\ [Instituto Superior de Música (UNL)]
}

Resumen A lo largo de más de 30 años la ciudad de Santa Fe (Arg.) ha desarrollado una fuerte actividad artística dentro del género del jazz. Cuenta con importantes festivales dónde el jazz ocupa un rol protagónico, como son El Festival de Jazz de Santa Fe, Trombonanza y también el Festival internacional de Percusión. Estos eventos han traído grandes figuras del género como Paquito D' Rivera, Conrad Herwig, Jeff Gardner, Ernesto Jodos, “Fats” Fernández, Remiggio Pereyra Pintos, entre otros.

Dentro de este panorama la guitarra de jazz fue acompañando el proceso evolutivo del género en la ciudad. En su recorrido diversos guitarristas realizaron importantes aportes para la comunidad santafesina del jazz y compartieron sus aprendizajes con nuevos interesados en el instrumento. Así se fue formando un árbol genealógico donde los años comenzaron a manifestar diferentes generaciones de guitarristas.

Éstas generaciones, sus principales actores, la relación entre ellos y sus influencias mutuas, sus historias de vida y su aporte para el circuito de jazz de Santa Fe entre los años 1955 a 2005 serán las temáticas de este artículo.

Palabras clave: Jazz · guitarra · Santa Fe
Summary For more than thirty years, a vast artistic activity within the jazz genre has developed in the City of Santa Fe (Argentina). It holds major festivals where jazz plays a leading role, like the Santa Fe Jazz Festival, Trombonanza, and also The Percussion International Festival. These events have brought in top musicians like Paquito D'Rivera, Conrad Herwig, Jeff Gardner, Ernesto Jodos, “Fats” Fernández, Remiggio Pereyra Pintos, just to mention a few. In this context, the jazz guitar has been supporting the evolutionary process of the genre within the city.

Along the way, several guitarists contributed substantially to the jazz community of Santa Fe and shared their knowledge with people who started showing interest in the instrument.

Little by little a genealogical tree began to form and over the years, several generations of guitarists have emerged.

These generations, their key characters, their relationship and mutual influence, their life stories, and their contribution to the jazz production from 1955 to 2005 will be the topics of this article.

Keywords: Jazz · guitar · Santa Fe 


\section{INTRODUCCIÓN ${ }^{1}$}

Diversas fuentes dan cuenta de que los primeros indicios de la aparición del género jazz en el país datan de la década del $20,{ }^{2}$ mientras que en Santa Fe encontramos alguna referencia recién hacia los años $40^{3}$. Sin embargo, como veremos parcialmente en el presente escrito, la proyección del jazz de la ciudad de Santa Fe es importante y de referencia para todo el país. Aproximadamente podemos hablar de unos treinta años de intensa actividad con festivales de jazz ininterrumpidos ${ }^{4}$, un festival internacional de trombones (Trombonanza) y también el festival internacional de percusión. Estos tres eventos han traído grandes figuras del jazz internacional y nacional, tales como Paquito D' Rivera, Conrad Herwig, Jeff Gardner, Ernesto Jodos, «Fats» Fernández, Remiggio Pereyra Pintos, Daniel Maza por mencionar unos pocos. Santa Fe también tiene una big band de jazz estable (Santa Fe Jazz Ensamble ${ }^{5}$ ), otra big band con jóvenes músicos interesados en aprender el género (Santa Fe Jazz Ensamble Jr.), jam sessions y múltiples presentaciones durante todo el año. A su vez, numerosos músicos de jazz santafesinos tuvieron la oportunidad de desarrollar su carrera fuera de la provincia, prin-

1 El presente artículo corresponde parcialmente a una investigación de campo iniciada en 2018, de un total de 70 pag. 2 En su libro Jazz Argentino (2015) Berenice Corti comenta al respecto: «En los años veinte la American Jazz Band de Eleuterio Yribarren compartía anuncios en la revista Caras y Caretas [...] con Carlos Gardel, mientras que Roberto Firpo y Franciso Canaro presentaban sus orquestas Típica y Jazz-Band" (Cortil, 2015: 36) en Jazz Argentino (2015). "1914. Eleuterio Yribarren funda la Jazz Band Eleuterio Yribarren (luego American Jazz Band).-1920. Francisco Canaro y Roberto Firpo, líderes de orquestas de tango, comienzan a dedicar parte de sus repertorios al jazz" (Corti, 2015: 170). Sergio Pujo en Jazz al Sur (2004) escribió: «Todo esto era anunciado en las publicaciones de gramófonos y de catálogos discográficos en los que, junto a Gardel-Razzano y Lola Membrives aparecía Roberto Firpo haciendo tangos...y jazz. [...] Las primeras nociones de jazz que conocimos un grupo de muchachos nos las dieron los primeros discos Victor, años 1918 a 1922" (Pujol, 2004: 19).

3 En la década del 40/50 existían las llamadas "orquestas características». El baterista santafesino Raúl H. Goldsack en libro no editado llamado La Batería comenta: «Me compré una batería [...] -estamos hablando del año 1948- [...] y en aquella época las orquestas eran lo que se llamaba 'orquestas características', que no era solamente de jazz o rock, hacían todos los géneros populares, foxtrot, vals, paso doble corrido, el himno nacional, tangos, Gershwin, de todo un poco" (Goldsack, 1995: 7).

4 En 2019 el festival de jazz de Santa Fe realizó su edición №22. En 2020 fue la primera vez que el festival se vio interrumpido debido a la pandemia del COVID-19.

5 A partir de aquí «SFJE». La misma se consolidó hacia finales de la década de 1980 pero tiene sus comienzos en el año 1981. Es una organización sin fines de lucro formada por amigos y movilizada por el placer de tocar jazz en formato Big Band. La misma organiza diversos eventos en la ciudad relacionados al jazz (Festival de Jazz, Trombonanza, etc.) y sus músicos son seleccionados en base a su desenvolvimiento dentro del género y al vínculo de amistad que existe entre los integrantes y sus aspirantes. 
cipalmente en Buenos Aires y fuera del país. Tal es el caso de Francisco Lo Vuolo, Carlos Michellini, Horacio Blanc, Adrián Barbet, Pablo De Luca, Sebastián López, Cristian Bortoli, entre otros.

Dentro de este panorama, nuestro trabajo se enfoca en el mundo de la guitarra jazz en la ciudad de Santa Fe. Los actores principales, considerados como referentes en dicho ámbito, son el eje de nuestra investigación. En ese sentido, nos proponemos destacar la forma en que algunos de ellos han realizado aportes importantes y significativos para la comunidad jazzística santafesina.

El objetivo del artículo es reconstruir el recorrido de la guitarra jazz en Santa Fe. Pensar una posible narrativa del pasado mediante un ordenamiento genealógico y generacional. Así también exponer los vínculos establecidos entre los guitarristas y dar cuenta de algunos hechos culturales importantes para la ciudad que fueron el resultado de dichos vínculos.

Anteriormente, la investigación que dio origen al presente artículo, daba cuenta de cuatro generaciones de guitarristas, divididas a su vez en sub-generaciones. Los cortes generacionales establecidos denotan por un lado las características vitales de los protagonistas pero sobre todo sus años de mayor trascendencia en la ciudad. Para el presente documento, hemos decidido enfocarnos en las dos primeras generaciones y mitad de la tercera debido a razones de espacio, sin embargo, proyectamos a futuro un segundo artículo que exponga el resto de las generaciones.

Las dificultades para establecer la categoría de 'principales actores/ intérpretes' de la guitarra jazz en Santa Fe son claras. En este sentido, en el marco del presente artículo, los criterios fueron:

$\sim$ Que el guitarrista haya poseído una intensa actividad grabando discos y/o tocando el género de jazz en espacios culturales y comerciales en vivo.

$\sim$ Haya enseñado a otros músicos (guitarristas o no) el género de jazz o alguna característica musical arraigado al mismo (improvisación, ensamble, swing feel, etc.)

$\sim$ Sea reconocido y nombrado por sus propios pares músicos y profesionales del ambiente como un exponente de la escena jazz en Santa Fe. 
El estudio de la música jazz en la ciudad de Santa Fe ha ingresado recientemente en la preocupación de investigadores, periodistas y artistas por lo que la información que se tiene es algo escueta ${ }^{6}$. Algunas producciones vinculadas al tema son: los Apuntes de jazz que emitió la Secretaría de Cultura de la unL desde el año 20Io, la producción filmográfica Noches de jazz (2002) realizada por Hermanos Marea Corps y el documental de Raúl Beceyro, Jazz: Imágenes de Santa Fe II (2007) ${ }^{7}$. Por último, dentro de las fuentes mencionadas, no vislumbramos ninguna referencia que haga hincapié a la guitarra Jazz en Santa Fe. Debido a esto, la metodología de la investigación ha estado fuertemente basada en la pesquisa hemerográfica, el trabajo de $\operatorname{archivo}^{8}$ y sobre todo en el uso de entrevistas semi estructurales con los guitarristas y sus familiares o conocidos, músicos del ambiente, periodistas y críticos musicales que se hayan considerado pertinentes para este trabajo.

Dentro de este panorama es que consideramos importante seguir aportando al estudio y al corpus de la música popular santafesina, ya que el jazz constituyó, y lo sigue haciendo, una parte importante de la escena musical de la ciudad.

\footnotetext{
6 Podemos comprobar esto consultando la Biblioteca Centralizada de FHUC - FADU - ISM, Biblioteca Municipal «Profesor Enrique Muttis", Biblioteca Pedagógica y popular "Domingo Faustino Sarmiento", Biblioteca «Dr. José Galvez", archivos periodísticos del diario El Litoral, periódico "El Paraninfo", redes sociales de la Jazz Ensamble así como su sitio web, algunas informaciones subidas a la página web del gobierno de la ciudad, los fascículos "Proyecto Aula» de la secretaria de cultura de Santa Fe, el libro La música en Santa Fe (1973) de Pérez Chiara y las revistas de divulgación musicológica del Instituto Superior de Música.

7 También se encuentra el trabajo de investigación de Darío Casanovas para el ISM, «Santa Fe Jazz Ensamble. Hacia una descripción de su recorrido histórico" (2012). Disponible en la Biblioteca Centralizada de FHUC - FADU - ISM. 8 Biblioteca Centralizada de FHUC - FADU - ISM, Biblioteca Municipal "Profesor Enrique Muttis", Biblioteca Pedagógica y popular "Domingo Faustino Sarmiento", Biblioteca "Dr. José Galvez", Museo Histórico "Marta Samatan", diario El Litoral, periódico "El Paraninfo" redes sociales, sitios web (Jazz Ensamble, Gobierno de la ciudad, Universidad Nacional del Litoral, etc.).
} 


\section{1 - LAS DOS PRIMERAS GENERACIONES. DEL 55 AL 85}

Para el intérprete musical santafesino de mediados del siglo xx existían, en principio, dos instancias de trabajo: las bandas (primordialmente la de policía ${ }^{9}$ ) y el llamado «mundo de la noche» (boliches y cabarets). En la entrevista realizada a Ángel "Cacho» Hussein, guitarrista de renombre de la ciudad, el mismo declara: «Los lugares "de noche” eran para un público adulto, de más de 30 años. Era un ambiente distinto, bohemio. Te podías encontrar artistas, intelectuales, escritores, de todo" (Hussein, 20I8). Allí era probable que el músico quedara meses contratado por el dueño por lo que pasaría una considerable cantidad de horas tocando y formándose técnicamente: «Tenías que meter oreja, leer cifrado, transportar al toque porque caían muchos cantantes. También acompañabas al mago, al cómico o a la mina que hacía el strip tease» (Hussein, 2018). Trabajar en estos espacios era una aspiración propia de la época ya que gozaban de tal fervor que llegaban a funcionar hasta cinco o seis días a la semana.

Por otro lado, el músico argentino popular no acostumbraba a identificarse con una clasificación genérico-musical tan delimitada como quizás sucede en la actualidad. La mayoría no solía auto percibirse como «jazzero», «tangero» o "folklorista» sino que eran músicos en general y sus conocimientos les permitían defenderse en los géneros bailables del momento (tango, bolero, folklore, danzón, malambo, melódico....y «algo» de jazz). «No existía en Santa Fe "el” lugar para escuchar jazz. Se tocaban algunas canciones de jazz [...] pero entre medio de los boleros, los tangos...» (Hussein, 2018). Al respecto Pujol escribe: «Los intérpretes argentinos de jazz no nacieron de la explosión espontánea de un grupo de aficionados a los discos [...]. Pensemos en los cambios acaeci-

9 La banda municipal todavía no existía. Aparece en 1981. Existían también otras bandas de barrio o de iglesias pero aficionadas. La secretaría de cultura de la ciudad en su Proyecto Aula-Ciudad / Fascículo No 4. Banda Municipal (2009) dice al respecto: "Las retretas en la Plaza de Mayo, en la Plaza San Martín o en el Boulevard Gálvez animan las tardes santafesinas y, en ellas, destacados músicos dirigen la Banda de Policía, la de los Guardiacárceles o la Banda Lisa del Piquete de Vigilantes. Esta última lo hace principalmente en los festejos patrios inundando los aires con alegres marchas militares. Además, actúan por entonces las bandas del Coliseo Taurino, del Círculo de Obreros Católicos, del Colegio de la Inmaculada, y de los teatros Municipal, Argentino y Politeama y de las sociedades italianas" (Secretaría de Cultura de Santa Fe, 2009: 4). 
dos por entonces en los repertorios de Roberto Firpo y Osvaldo Fresedo. Las orquestas que estos músicos lideraban eran de tango, qué duda cabe. Pero actuaban en cabarets y teatros para una audiencia que empezaban a clamar por esa música americana ${ }^{10}{ }_{\text {}}$ (Pujol, 2004: 20)

Sobre dicho contexto histórico nacerán las primeras raíces de la guitarra jazz en Santa Fe. Nuestro recorrido comenzará con la aparición de lo que consideramos los primeros dos referentes del instrumento en la ciudad: Horacio «Lalo» Blanc y Samuel «Poroto» Mehaudy.

\subsection{Primera Generación. Samuel}

\section{"Poroto» Mehaudy y Horacio «Lalo» Blanc}

Samuel «Poroto» Mehaudy nació en Calchaquí provincia de Santa Fe, en el año $1925^{11}$. Sus padres no eran músicos ${ }^{12}$ pero esto no le impidió acercarse a la música desde un lugar lúdico y recreativo. Tal es el caso que «Poroto» nunca se formó institucionalmente ni en el Liceo Municipal Antonio Fuentes del Arco ni en el Instituto Superior de Música ${ }^{13}$, los dos espacios de formación académico-musical en la ciudad de Santa Fe. No obstante esto no le impidió, por ejemplo, aprender a leer y escribir música ya que, según comentan los entrevistados ${ }^{14}$, Mehaudy era un óptimo guitarrista, de «mucho oficio». La transmisión oral, el contacto con otros músicos y la oferta laboral musical propia de la época (cabarets) lo llevaron a desenvolver su técnica y el aprendizaje de diver-

10 Dicha "aclamación" sería más propia de un público porteño. En Santa Fe llevó algo más de tiempo hasta que apareciera gente interesada en escuchar jazz.

11 Las informaciones que aparecen a continuación acerca de Samuel Mehaudy provienen de una serie de entrevistas realizadas en el marco de la presente investigación. Ver bibliografía.

12 No obstante, su hermano Guillermo Mehaudy (1921 - 1983), también fue un guitarrista de jazz de cierto reconocimiento. Formó el grupo "Panamericana Jazz junto a AUT Norton» (El Litoral, 2001: https://www.ellitoral.com/index. php/diarios/2001/08/17/pantallayescenarios/PAN-02.html [Consultado el 14/08/2020]).

13 "Avanzado el siglo XX, las políticas culturales públicas asumen un rol preponderante y surgen en la ciudad bajo tutela estatal organismos musicales estables, como la Academia de Canto, Música y Declamación del Liceo Municipal "Antonio Fuentes del Arco" (1928), el Instituto Superior de Música de la Universidad Nacional del Litoral (1947), la Orquesta Sinfónica Provincial de Santa Fe (1956) y la Escuela Provincial de Música 9901, que integra la Orquesta de Niños (1960)" (Secretaría de Cultura de Santa Fe, 2009: 4).

14 Entre ellos Ángel Hussein, Virgina Mehaudy, Roberto Maurer y Pedro Casís. 
sos géneros. Su hija Virginia Mehaudy comentó que «A mi viejo le gustaba el jazz. Escuchaba mucho jazz, aunque en sus shows había boleros, bossa nova, tangos y folklore también» (Mehaudy, 20I8).

Samuel Mehaudy compartía el oficio de la música junto a su esposa, la cantante Elsa Villot, más conocida como «Marianne» ${ }^{15}$. Juntos se presentaban en Santa Fe hasta que a principios de la década de 1950 viajaron a Buenos Aires donde vivieron por veinte años. Allí Mehaudy realizó una carrera considerable. Su trabajo consistió en tocar para la orquesta estable de Canal I3 y acompañar a "Marianne» cuando ella en los '60 grabó en el reconocido sello Microfón. También llegó a compartir escenario repetidas veces con el aclamado grupo de jazz Swing Timers, conjunto que «fue a lo largo de los '70 [...] una feliz prolongación del jazz clásico» (Pujol, 2004: 2I4). Familiares de Mehaudy y Roberto Maurer ${ }^{16}$ relatan anécdotas de que «Poroto» era muy solicitado al punto que lo buscó Sandro para que lo acompañara y cuando venía Roberto «El Polaco» Goyeneche a Santa Fe era a él a quien buscaba para sus shows ${ }^{17}$. "Para ellos [los porteños] Santa Fe era "Poroto"» (Maurer, 2018). A su vez, fue clasificado por la mayoría de los entrevistados en esta investigación como «el guitarrista de jazz en Santa Fe antes de "Cacho" [Hussein]». En este sentido el aporte de Mehaudy es claro, no solo por traer a Santa Fe toda aquella experiencia vivida en Buenos Aires, en una época donde el jazz porteño gozaba de gran inspiración con artistas del calibre de «Lalo» Schifrin, «Gato» Barbieri entre otros, sino que también, como veremos más adelante, permitió el enlace entre las generaciones posteriores de guitarristas de jazz santafesinos.

15 "Ella es una reconocida artista de Santa Fe que ha recorrido múltiples escenarios de nuestro país, de Brasil (San Pablo, Santos, Guarayá) y Uruguay (Montevideo) [...]. También cantó en radio y en la televisión porteña en una banda de Jazz dirigida por Dan D'Angelo y que integraba el Gato Barbieri [...]. Fue invitada a cantar con un de las pocas grandes bandas del país, la [Santa Fe] Jazz Ensamble." (Santa Fe Ciudad, 2012: http://www.santafeturismo.gov.ar/ web/posts/tangos-y-boleros-en-el-mercado-norte-217.php? $p=60$ [Consultado el 14/08/2020].

16 Uno de los primeros integrantes de la SFJE y periodista de gran importancia para el género de jazz en la ciudad. Ha tenido diferentes programas de radio, escrito en el diario El Litoral y editado algunos libros al respecto.

17 Cuando venía Goyeneche [a Santa Fe] lo íbamos a escuchar a Bacan y habitualmente lo acompañaban «Poroto" y Villalba. Y yo los veía y se entendían con Goyeneche. Se hacían jodas. Estaban haciendo La última Curda y "Poroto» agarraba y se lo empezaba a "valsear» [a tocar a la manera de un vals] y Goyeneche lo miraba y se reía. Es decir había una complicidad de tipos que se conocen" (Maurer, 2018). No se ha encontrado hasta el momento otra fuente que respalde la información. 
«Poroto» $\mathrm{y}$ «Marianne» vuelven a Santa Fe en el año 1972 y comienzan a tocar acompañados de diferentes músicos de la ciudad ${ }^{18}$ en diferentes bares, confiterías y boliches. Entre ellos, podemos mencionar $L a$ Cortada, Casablanca, Maritimo y Bacán. Luego «Poroto» comenzó a trabajar como copista de la orquesta sinfónica de la ciudad a la par que daba clases particulares. Hacia 1975/76 comienza a darle clases a Ángel Hussein. Con él, Hussein vio sus primeros conceptos de jazz y mantuvo una relación de mucho respeto y aprecio. Se traza aquí el primero de nuestros vínculos históricos que aparece en el «árbol genealógico» de la guitarra jazz de Santa Fe. La importancia de aquellas clases es incalculable ya que, como veremos, Hussein sería posteriormente uno de los principales referentes en la historia del jazz santafesino.

Hacia el final de su vida, «Poroto» continuaba trabajando en aquellos cabarets y boliches nocturnos viviendo una vida propia de «la noche». «Lamentablemente mi viejo no se cuidaba mucho. Andaba mucho por la noche, tomaba, fumaba. Pero siempre se mantuvo activo con la música, nunca dejó de tocar» (Mehaudy, 20I8). Samuel Mehaudy falleció en Santa Fe capital en el año 1994.

Por otro lado, encontramos un segundo exponente de la guitarra jazz casi contemporáneo a «Poroto». Horacio «Lalo» Blanc nació en $1942^{19}$. Desconocemos cómo fueron sus comienzos con la música y menos aún con el género de jazz ya que Blanc no se mostró particularmente interesado a contribuir con algunos puntos de nuestra investigación. Solo se limitó a decir que «El jazz se aprendía a través de los discos» (Blanc, 20I8). El segundo registro que tenemos al respecto es extraído de la entrevista realizada al periodista Roberto Maurer: «Nadie tocaba jazz en Santa Fe. Los únicos que tocaban a principio de los '6o eran "Lalo" Blanc en Guitarra, el "Tito" Guevara en Batería y "Jhonny” Nizo un pianista de Rafaela. [...] No hacían boleros, tangos ni nada de eso. Ellos eran un grupo de jazz» (Maurer, 2018). A su vez, Pedro Casís ${ }^{20}$ también men-

18 Entre ellos el hermano de "Poroto" Guillermo Mehaudy, Adolfo Villaba entre otros.

19 Las informaciones que aparecen a continuación acerca de Horacio Blanc provienen de una serie de entrevistas realizadas en el marco de la presente investigación. Ver bibliografía.

20 Pedro Casís es un importante referente para la tradición jazzística santafesina. Es director y uno de los

miembros fundadores de la SFJE. 
cionó este trío pero no ha sido posible identificar el nombre del conjunto. Sin embargo, el aporte de Blanc es en este sentido clave. Tener un grupo que se dedique solo a tocar jazz en aquella época era algo realmente peculiar para la ciudad. A su vez recordemos que, hacia i950, 'Poroto' ya se había radicado en Buenos Aires, por lo que durante toda esta década Blanc parece haber sido el único guitarrista específicamente de jazz de Santa Fe.

Además de músico, Blanc era también periodista y a comienzos de los '6o viajó a Buenos Aires para profundizar en ambos oficios. Al respecto comentó: «El jazz fue una pasión mía desde muchacho. Cuando cumplí i8 años me fui a Buenos Aires a estudiar y trabajar. En Santa Fe no había nada [de jazz]. A "Poroto" lo conocí en Buenos Aires y me ayudó bastante» (Blanc, 2018). Es verdad que Santa Fe carecía de espacios laborales y culturales en masa para el músico popular de aquella época. Frente a esto, Buenos Aires era la alternativa por excelencia para todo instrumentista del interior del país. Allí «Lalo» supo desenvolverse con soltura. En ese sentido, Hussein afirma: «En Buenos Aires tocaba con los músicos del ambiente del momento. Entre ellos el "Gato" Barbieri y Rodolfo Alchourron ${ }^{21} »$ (Hussein, 20I8). También tocó como guitarrista estable del famoso grupo Los 5 latinos y de hecho se lo puede ver junto a ellos en la película Viva la Vida (1969) de Enrique Carreras.

Luego de su paso por la capital, Horacio se mudó a New York donde se encuentra radicado hasta la actualidad. Allí trabajó entre 1998 y 2008 en La Prensa, "el periódico en español de Estados Unidos más antiguo, que se distribuye desde 1913 en Nueva York» ${ }^{22}$.

De aquellas épocas, en la plataforma de videos YouTube, encontramos un video ${ }^{23}$ de Blanc en 1986, en una clínica de la marca Sam Ash Music, acompañando a un guitarrista estadounidense llamado George Bien. Curiosamente en el $\operatorname{blog}^{24}$ de dicho guitarrista puede leerse acerca del video: «Una improvisación super rápida sobre el standard "Cherokee”.

21 No fue posible encontrar ninguna formación estable entre Blanc y los músicos aquí mencionados. Posiblemente hayan compartido una jam session o algún encuentro musical casual en Buenos Aires.

22 Wikipedia, 2008: https://es.wikipedia.org/wiki/El_Diario_La_Prensa [Consultado el 09/08/2020]

$23 \mathrm{https} / / /$ www.youtube.com/watch?v=fGFt-OaQeYY [Consultado el 09/08/2020].

24 http://www.georgebien.com/musicsound/musicsound.html [Consultado el 09/08/2020]. 
George es acompañado otra vez por Horacio Blanc, guitarrista de Julio Iglesias, Chico Hamilton y Tito Puente» ${ }^{25}$ (Bien, 1998$)^{26}$. Otras referencias de su trabajo en el extranjero aparecen junto a Pijuán y su sexteto en el Tradewinds Borinquen en el vinilo «El Florón» de $1966^{27}$; junto a Mandy Vizoso como arreglador y director musical del disco «Roberto Yanes interpreta a Chango Alvarado» de 198028; y con Enrique Quagliano tocando tango en Nueva York en los noventa ${ }^{29}$.

Finalmente, la última referencia que tenemos de Blanc es del año 20Io. En aquella ocasión, se presentó en el Festival de Jazz de Santa Fe, en La noche de los maestros ${ }^{30}$. Este dato no es menor ya que el reconocimiento de uno de los símbolos del jazz más influyentes de la ciudad como lo es la $S F J E^{31}$ denota en parte la importancia de nuestro guitarrista.

Podemos concluir que, si bien el aporte más claro de Blanc para Santa Fe parece haber sido su actividad previa a su viaje a Buenos Aires, el constante reconocimiento de sus pares, junto a su desempeńo internacional y su influencia en otros músicos santafesinos, lo clasifica decididamente como un referente de peso para la ciudad.

\section{$1.2 \cdot$ Segunda Generación. Ángel "Cacho» Hussein}

Posteriormente a la época donde el músico santafesino promedio de formación popular trabajaba principalmente en cabarets y boliches, comienzan a generarse otros espacios donde el artista pudo desenvolverse. Hacia

\footnotetext{
25 "A super-fast improvisation on the standard, 'Cherokee'. George is again accompanied by Horacio Blanc, guitarist for Julio Iglesias, Chico Hamilton and Tito Puente» (Traducción no oficial por Oscar Castellano).

26 Los artistas aquí mencionados por Bien son de renombre, sin embargo, no fue posible corroborar dicha información.

27 https://www.popsike.com/PIJUAN-Y-SU-SEXTETO-EN-EL-TRADEWINDS-BORINQUEN-1039-1966-ORIGGREAT-HEAR/291651702847.html [Consultado el 01/01/2021]

28 https://diazayalacollection.fiu.edu/sites/diazayalacollection.fiu.edu/files/SECCIONO6V.pdf [Consultado el 01/01/2021].

29 https://www.nytimes.com/1997/01/19/nyregion/clue-to-global-warming-the-tango-is-coming-back.html [Consultado el 01/01/2021].

30 Se trató de una noche donde la propia Santa Fe Jazz Ensamble homenajeó a "sus maestros». http://www.santafeciudad.gov.ar/noticia/maestros_catedra_festival jazz [Consultado el 11/08/2020])

31 Santa Fe Jazz Ensamble.
} 
la década del 70 en Santa Fe aparecen algunos centros artísticos o incluso bares que admiten la interpretación de música en vivo. Marianne, esposa de Samuel 'Poroto' Mehaudy, cuenta en una nota al diario El Litoral el primero de septiembre de $2007^{32}$ :

Mi marido era un inventor de lugares, como «La Cortada», que quedaba atrás de la Universidad Católica [...]. Podías estar meses tocando y cantando. Había otro lugar que se llamaba "Casablanca», en la galería donde estaba el cine Chaplin [...]. Otro lugar hermosísimo era "Marítimo», en San Jerónimo casi Tucumán: aunque fuera miércoles a la noche e hiciera frío, se llenaba (Marianne, 2007).

No obstante cabarets y boliches no desaparecieron de un momento al otro, por lo que muchos artistas que crecieron en aquel ambiente preferían seguir trabajando allí, a la vez que no encontraban interés en llevar el jazz a otros espacios de la ciudad. Pedro Casís comentó en la entrevista que, en la posterior prosperidad de la $S F J E$, algunos músicos más antiguos no se quisieron sumar al nuevo movimiento que la big band estaba impulsando en la ciudad. No participaban de los festivales ni aceptaban las invitaciones para tocar en vivo.

En cuanto a la escena del género a nivel nacional, a modo de contextualización, en su libro Oscar Alemán. La guitarra embrujada (2015) Sergio Pujol cuenta sobre la llegada de Duke Ellington a la Argentina en I968:

Quizá no era el mejor momento para el jazz en el mundo. No gozaba el fervor popular de otros tiempos. Lo habían desplazado del centro de la escena el rock y la música pop. [...] En 1968, los argentinos de fama internacional eran Lalo Schifrin, convertido en exitoso compositor de cine, y Leandro "Gato" Barbieri, por entonces figura del free jazz europeo. Enrique «Mono» Villegas había tenido su cuarto de hora internacional, viviendo y grabando discos en Nueva York (Pujol, 2015:265-267).

32 http://www.ellitoral.com/index.php/diarios/2007/09/01/nosotros/NOS-02.html [Consultado el 11/08/2020]. 
Dentro de este contexto, después de que «Poroto» fuera el referente de la guitarra jazz en Santa Fe por tantos años (1970 a 1980 aproximadamente), aparece en escena el joven guitarrista Ángel «Cacho» Hussein. Él se convertiría en una de las figuras más importantes, respetadas y de mayor influencia dentro del jazz en la ciudad.

Ángel Hussein nació en el año $1958^{33}$ en Santa Fe en una casa de familia donde nadie ejercía profesionalmente el oficio de músico. En la entrevista realizada cuenta que «Usaba la guitarra de juguete de mi hermanita para sacar melodías hasta que mi viejo me compró una criolla» (Hussein, 20I8). Así, comienza sus primeras clases de guitarra en I973 y entre los años 1975/76 decidió tomar clases con «Poroto» Mehaudy. En dichas clases «Cacho» tuvo su primer acercamiento al jazz estudiando lectura de cifrados, algo de improvisación, la habilidad de «mutear» ${ }^{34}$ cuerdas (recurso básico para tocar y acompañar al estilo de Freddie Green ${ }^{35}$ ) y otros conocimientos generales. “"Poroto” era la única persona en Santa Fe que tenía algún tipo de conocimiento de jazz aplicado a la guitarra» (Hussein, 20I8). No obstante, las clases se desenvolvían a través de una modalidad muy informal y para nada sistemática. «Cacho» comenta al respecto:

Tomar clases con «Poroto» era ir a la casa a hablar con él [...] Incluso podías estar un buen rato esperándolo, porque ibas a las 5 pero hasta las 6 el tipo no se levantaba de dormir la siesta [...] No era el concepto de «el» profesor como hay ahora [...] A veces se sentaba a charlar con vos con un vaso de whiskey en la mano [...]. No era una cosa de seguir un plan, él te iba hablando de lo que se le ocurría y te iba mostrando (Hussein, 20I8).

33 Las informaciones que aparecen a continuación acerca de Ángel Hussein provienen de una serie de entrevistas realizadas en el marco de la presente investigación. Ver bibliografía.

34 "Mutear" viene del inglés mute que significaría «mudo». Esto es silenciar o apagar algunas de las cuerdas de la guitarra sin que molesten a las demás cuerdas que sí deben sonar.

35 Freddie Green fue el guitarrista principal que acompañó por muchos años a la orquesta de Count Basie y sobre la cual desarrolló una "escuela" en el armado de los voicings de los acordes que usaba y que fue referencia para la función de la guitarra aplicada a una big band. 
Es interesante reconocer los retazos que aún tenía «Poroto» de una época donde no circulaban en la ciudad métodos de jazz y donde los conocimientos se asimilaban en el hacer musical compartido con otros músicos o en el intercambio oral que allí se producía. Sin embargo, esto no fue una limitación para que dos generaciones diferentes conectaran y generaran el primer vínculo en nuestro «árbol genealógico» de la guitarra jazz santafesina. A partir de aquí Hussein empezó a interesarse cada vez más en el género y comenzó a estudiar guitarristas estadounidenses como Wes Montgomery, Joe Pass y George Benson. Todos ellos pertenecían a escuelas muy parecidas ${ }^{36}$ del jazz, dentro de los géneros conocidos como swing, be-bop y hard bop. El guitarrista santafesino de jazz «Muni» Puyol comenta: «Hubo una época que yo quería estudiar con "Cacho" porque son tipos que tienen la escuela del swing arriba» (Puyol, 2018).

No obstante, dicho swing no llegó solo estudiando a Montgomery, Pass y Benson. Con el paso de los años y las enseñanzas de "Poroto", Hussein comenzó a tocar en vivo en bares y cabarets de la ciudad y hasta pudo vivir los vestigios de aquella "vida nocturna". Hacia comienzos de 1980, comienza a reunirse con un grupo de aficionados de jazz, con el objetivo de escuchar bossa nova e intentar tocarla mediante un aprendizaje colectivo. Cacho cuenta al respecto: "Yo era cine-clubista y estaba en el cine "Chaplin". Salí de ahí a tomarme el colectivo y estaba el "Pata" Pereyra $^{37}$ y me dice "Che mirá, nos estamos juntando ¿Querés venir?"” (Hussein, 20I8).

De esta manera, comienza a tocar "Cacho» junto a Pedro Casís (trompetista), Ricardo Llusá (bajista), Miguel Demartini (batería), Roberto Maurer (saxofonista) y Daniel Darras (trombonista). Sin que lo supieran estaba naciendo la Santa Fe Jazz Ensamble (SFJE). Con ella iba a llegar el jazz a la ciudad de manera consciente ya que aparecieron músicos santafesinos preocupados por aprender a tocar un tipo de música con la cual se identificaban y comprometidos a ser los mejores músicos de jazz que podían ser. Aparece así un interés por el jazz que predominaba

36 En este sentido, quizás, Benson se diferencia un poco, posiblemente por ser más joven, ya que posee una de sus etapas donde vivió y experimentó la fusión del jazz con los géneros pop y soul.

37 Rafael "Pata» Pereyra. Saxofonista santafesino que falleció en 2013. 
sobre el resto de los géneros. Éste es otro cambio generacional de peso respecto de la época de «Poroto» y «Lalo».

Según Darío Casanovas, en su trabajo de investigación Santa Fe Jazz Ensamble. Hacia una descripción de su recorrido histórico: «La primera aparición en público [del ensamble] de la cual se tiene registro fue el 3I de diciembre de 198I" (Casanovas, 20I2: I2) y hacia I984 este conjunto de amigos aficionados al jazz ya tenía el nombre de Jazz Ensamble.

La aparición de la SFJE generó tal revuelo entre los músicos de la ciudad, que hacia 1985 "Cacho" se había convertido en el referente por excelencia de la guitarra jazz en Santa Fe, dentro del pequeño circuito jazzístico que allí se había gestado. Jóvenes guitarristas y músicos habían comenzado a acercarse a Hussein para pedirle clases de jazz debido al asombro que les producía escuchar el sonido de la SFJE en vivo. El reconocido pianista santafesino Francisco Lo Vuolo ${ }^{38}$, en una entrevista en el programa de televisión Desde el Saer, dice:

Yo la primer persona con la que empecé a tener una noción en el jazz y que me mostró un montón de cuestiones básicas que tienen que ver con la improvisación fue «Cacho» Hussein, que es el guitarrista del ensamble, y que es un maestro importantísimo para todos nosotros, para Seba $\left[\mathrm{López}^{39}\right]$ también, para Bruno [Rosado ${ }^{40}$, para todo el mundo. Y a partir de "Cacho» entré en el ensamblín [Jazz Ensamble $J$ r.] (Lo Vuolo, 2010 $\left.{ }^{41}\right)$.

A su vez la SFJE fue refinando su público y haciéndolo crecer a la par de que ganaban popularidad en la ciudad ${ }^{42}$. Crecieron hasta el punto de

38 Pianista. Uno de los músicos santefesinos de jazz más importantes que tiene la ciudad. Llegó a desarrollar una importante carrera en Buenos Aires. Actualmente integra la la Big Orchestra del famoso trompetista Mariano Loiácomo. 39 Guitarrista de jazz de Santa Fe.

40 Saxofonista de jazz de Santa Fe.

$41 \mathrm{https}: / /$ www.youtube.com/watch?v=2al4ZTuOcm4\&t=8s [Consultado el 09/08/2020].

42 Para más información respecto a la historia de la SFJE, ver: Noches de Jazz (2002, Hermanos Marea Corp.) [DVD]; Jazz: Imágenes de Santa Fe II (2007, Raul Beceyro)[documental]; Proyecto Jazz (2019, Diego Soficci) [película]; Apuntes de Jazz (SECRETARIA DE CULTURA DE LA UNL), Santa Fe Jazz Ensamble: Hacia una descripción de su recorrido histórico (2012, CASANOVAS); https://www.ate.org/artistas/cat_p/3/cat_h/15/val/47/santa-fe-jazz-ensamble.html; http://jazzensamble.tripod.com/; https://shagradamedra.com.ar/contenido/205/santa-fe-jazz-ensamble (Sitios web). 
generar en 1998, un festival de Jazz en la ciudad que al día de hoy sigue en pie y que ha contado con la participación de grandes referentes del jazz nacional e internacional. La aparición de una big band de jazz como también un festival son en suma una de las piedras angulares para lo que fue el posterior desarrollo del género en Santa Fe y la creación de espacios fundamentales como: la Jazz Ensamble Jr., el festival Trombonanza, las Jams Sessions, el Festival de Percusión, cursos y seminarios de jazz.

Posteriormente, la década del 90 le deparó a Hussein grandes acontecimientos. Por un lado ganó una beca de la provincia para estudiar ańo y medio con Rodolfo Alchourron en Buenos Aires. Por otro, hacia 1993, tuvo la increíble experiencia de poder tocar con Joe Pass en el patio catedral junto a la SFJE. Roberto Maurer habla al respecto en una nota que realizó para el diario El Litoral:

Terminó el concierto y, en lugar de quedarse a aceptar los saludos de músicos y admiradores, [Joe Pass] se dirigió a Cacho Hussein, el guitarrista de la orquesta, le dijo «vení» y se encerró con él en el camarín.

Al toque, me dio una clase», contó luego Hussein, que utilizaba una Epiphone de caja chica, semejante al modelo 335 de la Gibson de в в King. Joe Pass le recomendó una guitarra de caja más grande, de sonido más acústico, que debía usar con menos volumen de amplificador, pero con mano recia, a fin de alcanzar el acompañamiento rítmico liviano de Freddy Green, el gran experto en el rubro. (Maurer, 2008 ${ }^{43}$ )

Luego, como destacamos previamente, en el ' 96 aparece el primer Festival de Jazz de Santa Fe, el cual significó todo un acontecimiento para la ciudad. Así, los años pasaron y «Cacho» fue enseñando la música de jazz a una cantidad incontable de músicos santafesinos mediante clases particulares, master classes y la Jazz Esamble Jr ${ }^{44}$. Esta última es un

43 https://www.ellitoral.com/index.php/diarios/2008/10/25/nosotros/NOS-08.html [Consultado el 09/08/2020] 44 Es un espacio juvenil de formación musical mediante ensayos regulares (uno por semana) y conciertos en vivo organizados por sus integrantes y que son el único medio de financiamiento que poseen. El aprendizaje esta guiado por un repertorio de Big Band que propone el director (miembros de la SFJE) y que a lo largo de cada ensayo orienta la práctica de diversas cuestiones propias del género. Para ingresar debe abrirse una nueva vacante de instrumento y 
espacio de formación creado hacia 1998 donde jóvenes músicos integran una big band con la tutela de los miembros de la SFJE. Dicho espacio sigue en actividad hasta el día de hoy. Del compromiso adoptado por Hussein con la enseńanza del género salieron varios de los guitarristas de jazz que fueron tomados para esta investigación: Rubén Paolantonio, Pablo De Luca, Sebastián López, Gerardo Aznar, entre otros. El aporte de «Cacho» es en este sentido uno de los más valiosos.

Actualmente sigue formando parte de la SFJE con una actividad ininterrumpida de casi treinta ańos y posee un dúo junto a la cantante Nilda Godoy, que rinde homenaje al poeta y letrista mendocino Armando Tejada Gómez. En la entrevista, Hussein manifestó que actualmente está más ligado a la música argentina y particularmente al folklore, más que al jazz. «Para tocar jazz tenés que estar en contacto constante» (Hussein, 20I8). Ya no se dedica a dar clases particulares y está a pocos años de jubilarse de la orquesta de niños.

\section{2- Tercera generación. del 85 Al 2005}

Con la aparición de la SFJE llega el jazz de manera consciente a la ciudad y con ella Ángel Hussein se convierte en una de las referencias más importante de la guitarra jazz en Santa Fe. De él se desprenden todos los integrantes de nuestra tercera generación, ya que estos acudieron a "Cacho" para tomar sus primeras clases. Este primer impulso, de un joven Hussein al tomar sus primeras clases de jazz con «Poroto» Mehaudy, encuentra continuidad en los curiosos músicos que luego de escuchar al ensamble en vivo, se acercaban a hablar con "Cacho». En este sentido, para comprender esta nueva generación, debemos necesariamente contextualizar el panorama nacional e internacional del género.

Hacia la década del '8o el jazz en Estados Unidos estaba revisitando sus raíces a través de artistas comprometidos con la tradición del género.

audicionar. La convocatoria es anual, generalmente en el mes de marzo. El jurado está conformado por integrantes de la SFJE y quien ingresa normalmente conserva su puesto por dos años. En un principio quien finalizaba su ciclo en el Ensamblín era condecorado con un diploma pero hacia el año 2010 se interrumpió la entrega del mismo. 
En Historia del Jazz (1997) Ted Gioia comenta al respecto: «El resurgimiento de los estilos de jazz acústicos tradicionales en el mainstream bajo los auspicios de Wynton Marsalis figuraría como la evolución más publicitada -y acaloradamente contestada- del mundo del jazz en los ochenta y noventa» (Gioia, 1997: 409). No obstante en la Argentina el panorama poseía algunas divergencias. Durante la última dictadura militar a los artistas de jazz no exiliados los encontramos en dos vertientes musicales diferentes pero emparentadas: rock nacional y el llamado género «fusión». En Jazz Argentino (20I5), Berenice Corti explica:

Los años de la dictadura más cruenta de la historia argentina (19761983) silenciaron también la labor de numerosos artistas, por lo que muchos de ellos optaron por el exilio [...]. Mientras tanto, la eclosión del llamado rock nacional hacia 1982, en tiempos de la guerra de las Islas Malvinas, contó con varios músicos de jazz entre sus filas, militantes del sonido eléctrico de fines de los años setenta. La mutua colaboración se remonta a los inicios del rock argentino en grupos como Almendra [1967] [...] [donde] una década después [dicha unión] se lo relacionaba con el auge internacional del jazz rock (Corti, 20I5: 39).

Para Goia el jazz fusion o jazz rock describe «los diversos intentos de combinar el jazz con el rock» (Gioia, 1997: 391), compartiendo un sonido más eléctrico que el del jazz tradicional. Dicho género, es explorado hacia finales de los '6o y se desarrolla durante los '70 en Estados Unidos $^{45}$.

Esta amalgama de géneros llamó la atención de dos jóvenes guitarristas santafesinos. Pablo De Luca, quien en un comienzo desarrolló su interés por el género propiamente dicho de jazz fusion y Rubén Paolantonio, quien desde un lugar más filosófico y mediante la «fusión»

45 A su vez «el movimiento de la fusión jazz-rock, el legado de Davis, se consolidaba ahora como el estilo comercialmente más viable del momento" (Gioia, 1997: 393). El género es inaugurado por el disco Bitches Brew de Miles Davis (1970) y se expande "con tres grupos que demostraron ser especialmente influyentes: Return to Forever de Chick Corea, la Mahavishnu Orchestra de Joh McLaughlin y Weather Report, liderado conjuntamente por Wayne Shorter y Joe Zawinul» (Gioia, 1997: 394). 
de recursos intentó una aproximación musical que se aleje de la clasificación de géneros.

\section{1 - Tercera Generación (a). Pablo De Luca y Rubén Paolantonio}

Pablo De Luca nace en Santa Fe en $1965^{46}$. Su primera aproximación con la música viene a través del rock nacional y dicho interés lo lleva a comenzar a tocar la guitarra eléctrica: «Yo empecé con el rock nacional, como empezamos todos. Sui Generis y todo eso» (De Luca, 2018). Observamos entonces que desde el comienzo del aprendizaje de Pablo ( $\mathrm{y}$ veremos que de Paolantonio también) hay un interés por el instrumento de guitarra eléctrica que denota cierta divergencia con la generación anterior, ya que por ejemplo Hussein demoró diez años en conseguir una luego de empezar a estudiar con su guitarra criolla.

Posteriormente, hacia el final de la década, De Luca comienza a interesarse por el jazz a través de amigos más grandes que coleccionaban vinilos. «Me llamó mucha la atención los vinilos de [John] Coltrane, Miles Davis, Chick Corea, la Mahavishnu [Orchestra], esa onda. No entendía nada yo» (De Luca, 2018). Este descubrimiento lo lleva a formar un conjunto musical nuevo llamado «Toque Eléctrico». "Grabamos en lo de Forni ${ }^{47}$ y lo invité a Pedro Casís y a Rubén Carughi ${ }^{48}$ a grabar» (De Luca, 2018). A partir de este encuentro, en I990 Casís lo contacta para formar parte de un proyecto muy similar a lo que luego sería la Jazz Ensamble Jr.:

46 Las informaciones que aparecen a continuación acerca de Pablo De Luca provienen de una serie de entrevistas realizadas en el marco de la presente investigación. Ver bibliografía.

47 Adrian Forni tiene un estudio de grabación en Santa Fe que se llama Santa Fe Recording ubicado al norte de la ciudad en calle Domingo Silva Guzman al 1351.

48 Trombonista de la Jazz Ensamble y exdirector, de la Jazz Ensamble Jr. Es una figura muy importante para el jazz por su constante actividad en el circuito y por la formación de uno de los festivales más importantes de la ciudad: Trombonanza (Festival de trombones). 
Ya en esa época, algunos se sorprenden pero la Jazz Ensable Jr. estaba. Tenía otro nombre ${ }^{49}$ pero estaba. Ensayábamos en la Escuela Provincial de Música ${ }^{50}$ los sábados a las in de la mañana. Ahí tocaba Carlitos Michellini, tocaba yo y lo teníamos a "Cacho» atrás mío ayudándome a leer las partes. [Estaba] él, Pedro Casís, Victor Malvicino, [...] "Charly» Aveduto ${ }^{51}$. [...] «Cacho» supervisaba y ahí tomé unas clases con él (De Luca, 2018).

Hussein fue así la primera persona con la que De Luca estudió los conceptos básicos de jazz ${ }^{52}$. Si bien fueron unas pocas clases, De Luca manifestó que acudió a él "porque era el único guitarrista de jazz que había» (De Luca, 20I8). El contexto es entonces claro: en lo que respecta a la guitarra jazz, no se vislumbraba en principio otra referencia en la ciudad que no fuera la de Hussein. A su vez, Pablo viene a ser uno de los primeros alumnos guitarristas ${ }^{53}$ de «Cacho» que posteriormente desarrollarían una carrera musical seria en el jazz. En consecuencia, establecemos aquí nuestro segundo enlace generacional: Mehaudy «Hussein» De Luca.

No obstante, otro momento donde Pablo aprendía era cuando diversos músicos de jazz de Buenos Aires se acercaban a la ciudad para tocar en los ciclos de los Lunes del Paraninfo ${ }^{54}$, organizados por la Universidad Nacional del Litoral. Éste era quizás uno de los pocos espacios donde se podía llegar escuchar algo de jazz: «No había jam [sessions]. Había ciclos en el paraninfo [...]. Armabas un grupo y tocabas en el Teatro [Municipal de Santa Fe], porque no había lugares. O tocábamos en el

49 Desconocemos este "otro nombre». Sin embargo, probablemente sea "Combo de Jazz", el nombre que recibía un taller que dictaba Rubén Carughi por esos años, el cual se fue consolidando en su actividad hasta que en 1998 toma el nombre de Jazz ensamble Jr.

50 Calle Gobernador Candiotti al 3000.

51 Carlos Michelli (1967) es un importante saxofonista de jazz santafesino que tuvo la oportunidad de estudiar en Berklee College of Music y que ha desarrollado su carrera musical en Buenos Aires. Victor Malvicino y 'Charly' Aveduto (1966) son Saxofonistas de la SFJE.

52 También tomo clases con el bajista Mariano Ferrando sobre armonía y con Paco Gilbainez sobre guitarra clásica. 53 Los otros son Rubén Paolantonio, Sebastián López y Gerardo Aznar.

54 Desde la vuelta a la democracia y de manera ininterrumpida, los Lunes del Paraninfo [organizado por la UNL] es el ciclo de música que ha recibido a reconocidos músicos nacionales e internacionales en el mítico edificio de Rectorado. Han subido al escenario artistas de la talla de Liliana Herrero, Néstor Marconi, Juan Falú, Tonolec, Dino Saluzzi, [...] entre otros (UNL, sin fecha: https://www.unl.edu.ar/cultura/lunes-del-paraninfo/ [Consultado el 27/11/2018]). 
Centro Cultural [...]. Después había algún bar como ahora, hacías una movida, llevabas tu gente» (De Luca, 2018). En uno de estos ciclos ${ }^{55}$ se presentó el guitarrista Ricardo Lew. Luego de ese encuentro, De Luca comenzó a viajar esporádicamente a Buenos Aires para tomar clases. Así también llegó a tomar clases con Lito Epumer y Gary Barton. Podemos observar entonces que, al traer músicos de jazz, la ciudad comienza a manifestar cierto interés por el género. Dicho interés irá incrementándose, hasta que en 1996 se organiza el primer Festival de Jazz de Santa Fe.

Posteriormente, a mitad del año 1992 mediante la ayuda de Pedro Casís, De Luca obtiene una beca de la Berklee College of Music (Boston, Estados Unidos). Transcurre un año y medio juntando el dinero hasta que finalmente viaja en 1994. La beca era por un semestre, pero Pablo se quedó I3 ańos en Estados Unidos. Una vez allí, De Luca comenta que "A la par que estudiaba, aproveché para tocar en diferentes jam sessions y tomar clases particulares con Jerry Bergonzi. También trabajé acompañando cantantes y en los cruceros» (De Luca, 20I8). Finalmente, en el 2008 vuelve a la Argentina. Luego de su regreso toma clases con el guitarrista Pino Marrone, quien fue su último maestro formal en Buenos Aires. Ya establecido en Santa Fe, comienza a armar diferentes grupos con músicos del ambiente ${ }^{56}$ a la manera de dúos, tríos, cuartetos, etc. Los años pasaron y Pablo se fue reincorporando nuevamente al circuito musical de la ciudad, al tiempo que comenzó a vislumbrar nuevos guitarristas del género:

Lo conocí al Seba [López], incluso vino a casa a tomar una clase antes de irse a Buenos Aires [a estudiar al Conservatorio Manuel de Falla] [...], después lo conocí al Muni Puyol, después ya viene la generación de Pablito [Somaglia] y a Richard [Ricardo Ponce] ${ }^{57}$ lo conocí el anteańo pasado [2016] [...] Cuando yo me fui [a Estados Unidos] no había nada, había muy poco. Fuera del ensamble no había nada.

55 Probablemente en el año 1991.

56 Fernando Silva, Adrian Barbet, Luis Barbiero, Eugenio Zeppa, Bruno Rosado, Francisco Lo Vuolo, Gonzalo Carmelé, Pedro Casís, etc.

57 Todos ellos fueron tomados en cuenta para las generaciones posteriores de esta investigación. 
El jazz no existía. Me sorprendió [...] más que nada que vaya gente a escuchar (De Luca, 20I8).

Hacia el año 2017 formó un conjunto llamado Latitudes Trío junto a Luciano Stizzoli y Walter Yones, donde interpretan composiciones propias que fusionan la música brasilera, el jazz y diversos géneros latinoamericanos plasmados en 2019 en su disco debut "Tiempo de Espera». En la actualidad Pablo dicta clases particulares y recientemente grabó su disco solista «Textures» (2020) con grandes músicos de la escena del jazz santafesino. Entendemos finalmente que estos aportes discográficos, su fuerte actividad ininterrumpida, el estudio profundo dentro y fuera del país del género y su oficio como docente, hacen de Pablo De Luca un eslabón fundamental para el recorrido histórico de la guitarra jazz en Santa Fe.

El segundo referente de nuestra tercera generación es Rubén Paolantonio quien nace en Santa Fe en el año $1970^{58}$. Curiosamente lo primero que podemos decir de él es que no se considera guitarrista de jazz, pero sí conocedor del género. De hecho Rubén no se considera guitarrista de ningún género musical. «Siempre me pareció naturalmente que no tenía ganas de acotarme a un estilo [género musical] porque me gustaban todos» (Paolantonio, 2018). No obstante Paolantonio se encontró en una etapa de su vida escuchando, aprendiendo y tocando mucho jazz:

A mí siempre lo que me interesó del jazz obviamente era la cuestión armónica. De la riqueza que tenía eso y siempre me gustó la improvisación y esa era la situación que a mí me generaba las ganas de estudiar y escuchar jazz. [...] Pero después inmediatamente entendí que eso estaba en toda la música, que esa es la gran influencia del jazz en el mundo. Después yo lo escuchaba en ciertas cosas del rock, del blues, del folklore (Paolantonio, 20I8).

58 Las informaciones que aparecen a continuación acerca de Rubén Paolantonio provienen de una serie de entrevistas realizadas en el marco de la presente investigación. Ver bibliografía 
En cuanto al término fusión «Es lo más cercano a lo que se puede decir. Estaba bueno porque era abarcativo. Ahí adentro podés meter un montón de cosas sin entrar tanto en detalle, entonces te servía" (Paolantonio, 20I8). Esta concepción de la palabra «fusión» en la música, en tanto mixtura de diversos géneros musicales (y no la concepción de un género nuevo en sí mismo como lo era en Estados Unidos), es una definición muy propia de la Argentina. Al respecto María Inés López, Elina Goldsack y Hernán Pérez realizaron un importante aporte sobre el género de fusión en la ciudad. En su artículo «La música de fusión en la ciudad de Santa Fe (Argentina) en la década del '80» (20I0), publicado en las actas del IX Congreso de la Rama Latinoamericana de la IASPM (20I0) (Caracas, Venezuela), afirman:

El surgimiento de la música de fusión en Santa Fe tuvo un impulso particular con el advenimiento de la democracia en 1983 . Este proceso creativo fue consecuencia de la efervescencia política, las búsquedas identitarias y los alcances de una tendencia que se dio en todo el país. Se caracterizó por no pertenecer a un género específico, los músicos utilizaban elementos provenientes de diferentes lenguajes, hasta el momento claramente delimitados (Goldsack, López y Pérez, 20IO: 2I2).

Dicho esto, los comienzos de Rubén en la música se asoman hacia el año I984. Su familia no se encontraba constituida por ningún músico profesional, sin embargo su hermano producía un programa de radio donde pasaba música. Es él quien le hace escuchar por primera vez a Spinetta y desde ese momento Paolantonio decidió que iba a ser músico. En aquella época se encontraba transitando la tecnicatura de electro-mecánica en la Escuela Industrial y comienza a estudiar con una guitarra criolla en una escuela de barrio, donde aprende a leer partituras e interpreta sus primeras canciones. No obstante ya estaba interesado por el sonido de una guitarra eléctrica, pero en aquella época era realmente difícil adquirir una. «Era imposible, como hoy querer comprarte un Ferrari. [...] Y de pronto, en muy poco tiempo gracias al I a I de Carlitos Menem todo cambió. Yo la primer viola eléctrica decente que compré fue porque la 
cambié por el viaje a Bariloche» (Paolantonio, 20I8). Recordemos que lo mismo había sucedido con De Luca, el mundo se había convertido en un «torbellino eléctrico», por lo que la guitarra eléctrica pasa a hacer un nuevo objeto de atracción para los jóvenes. Tres años antes de terminar la secundaria (1987), Paolantonio comienza a estudiar con Ángel «Cacho» Hussein:

Él fue el que más me acercó al jazz [...]. Me enseñó cómo pensar para armar los acordes, las escalas [...]. En ese momento era lo que yo quería aprender por más que yo escuchara en ese momento punk, y a la vez me encantaba. [...] A mí me gustaba esa armonía [la de jazz] y era lo que «Cacho» sabía (Paolantonio, 20I8).

Hussein le dio clases por tres años y dichos conocimientos fueron la base del aprendizaje sobre la cual Paolantonio desenvolvería el resto de su carrera. No solo por ser el primer acercamiento que tuvo hacia el jazz, sino porque Rubén no tomaría clases regulares con ningún otro profesor hasta la actualidad ${ }^{59}$. Nuevamente observamos la importancia de una figura como Hussein, que funcionó como una puerta de acceso hacia un género en principio críptico y misterioso para los jóvenes músicos santafesinos. Este vínculo establecido entre "Cacho» y Paolantonio será el último de nuestro artículo, con él finalizamos la primera mitad del total de nuestro «árbol genealógico».

Al terminar las clases con Hussein y con ellas la secundaría, Rubén emprendió un viaje de aprendizaje solitario:

Yo me considero muy autodidacta en realidad. Terminé en el 89 la escuela, dejé de estudiar con "Cacho», me puse a estudiar solo, y en el 90 ya estaba dando clases. Fue la forma paralela de estudiar. La exigencia de dar clases me decía «Bueno, si yo quiero enseñar algo pri-

59 No obstante, en su currículum actualizado al año 2018 Rubén documenta que "Ha tomado clases particulares y participado en clínicas y cursos con importantes guitarristas como, Lito Epumer, Mike Stern, Jhon Stowell y Juan Falúm (Paolantonio, 2018: 1). 
mero lo tengo que saberlo». Entonces fueron los primeros io años de dar clases de matarme (Paolantonio, 2018).

A la par que Rubén comienza a trabajar en la docencia, emprende su carrera de músico instrumentista tocando con diferentes conjuntos musicales. Así conoció el mundo "de la noche», el cual pasado un año decidió abandonar, ya que acompañaba cantantes en diferentes bares nocturnos y fiestas donde esporádicamente se podía llegar a escuchar algo de jazz. «Había algunos bares con más onda dónde por ahí la gente iba a escuchar jazz ${ }^{60}$, pero eran poco concurridos» (Paolantonio, 20I8).

Por otro lado, otro mundo con el cual no sentía la necesidad de relacionarse era el de las instituciones. Los dos establecimientos preferenciales para estudiar música por aquel entonces eran el «Instituto Superior de Música y el Liceo Municipal Antonio Fuentes del Arco». Dichas instituciones en el año 90 enseñaban música clásica y dictaban la carrera del profesorado de música:

Yo quería ser músico, no profesor de música. Porque en realidad profesor de música $[\ldots]$ ya lo era [...]. Como me gusta tanto y como le puse tanta pila dije «Yo no voy a perder tiempo con eso». Quería tener tiempo para tocar, lo que yo quería tocar y con la gente que yo quería tocar (Paolantonio, 2018).

Paolantonio tampoco llegó a estar interesado en la participación de un espacio como la Jazz Ensamble o incluso la Jazz Ensamble Jr. ni las jam sessions que aparecieron posteriormente en la ciudad. Pablo Somaglia, alumno de Paolantonio durante diez años comenta: «Rubén hizo un camino aparte de la comunidad Jazz Ensamble [...]. Él se ha mantenido al margen de dicha comunidad de músicos. Él construyó su camino» (Somaglia, 2018). Según Rubén estas decisiones no se encuen-

60 Uno de esos bares era El Café de las Luces que se ubicaba debajo de lo que fue el Cine Arte Chaplin que por aquél momento se encontraba en la Galería Ross sobre peatonal. Cierra en 1998 junto con la galería. En dicho bar Rubén tocó con su banda Fata Morgana y Pablo De Luca con Toque Eléctrico. 
tran vinculadas a ningún aspecto peyorativo ni mucho menos, sino meramente personal.

Desde el año 2000 hasta la actualidad Paolantonio dicta clases en el Liceo Municipal. Luego de casi treinta años en docencia, Rubén aplicó sus conocimientos editando su primer libro: Armonía aplicada a la guitarra (2017). También dicta clases particulares y es un eslabón crucial entre las siguientes generaciones de nuestra investigación, ya que enseñó el género a Pablo Somaglia y «Muni» Puyol, ambos guitarristas de jazz santafesinos. A su vez, como músico ha realizado muchos proyectos ${ }^{61}$, grabado una considerable cantidad de discos ${ }^{62}$. En estos proyectos tocó con diferentes músicos que rondan el circuito del jazz ${ }^{63}$, el rock y el folklore santafesino. Dicho todo esto queda más que claro la importancia de Rubén Paolantonio para la guitarra jazz de Santa Fe y la necesidad de incluirlo en nuestro escrito.

\section{Conclusión}

Finalmente, podemos afirmar que el recorrido de la guitara jazz en Santa Fe posee vínculos fuertes, que permitieron una transición fructífera entre sus actores. También, podemos concluir que hubo un trayecto que tuvo continuidad: generó las conexiones pertinentes para que el circuito de la guitarra jazz en la ciudad siga enriqueciéndose. Hacia el final de este devenir histórico, vemos las fuertes influencias de aquellos guitarristas que ya no están sobre los que siguen estando, de manera que todos los participantes de este artículo están conectados directa o indirectamente. A continuación exponemos, el «árbol genealógico» de estas primeras generaciones:

611987 Viaje Astral. 1988 Antro Piaget. 1989 Fata Morgana .1991 La Gárgara. 1991 Haiku. 1992 Laberinto. 1993 Sergio Ramayo Grupo. 2001 Dúo Paolantonio-Barbet. 2002 Dúo Paolantonio-Huerta. 2005 Ruido Blanco. 2008 Paolantonio Grupo. 2012 Dúo Paolantonio-Rodriguez. 2013/2014 Dúo Paolantonio-Medina. Trio Paolantonio-Medina -Somaglia. 2015/2016 Grupo Kalma Mora.

622002 Noche de grillos. 2005 Ruido Blanco . 2008 Solo para todos (canciones para siempre). 2009 Rubén Paolantonio Cuarteto. 2016 Otra vuelta a la manzana . 2018 Intento Azul.

63 Pablo Somaglia, Ricardo Sosa, Francisco Cecchinni, Adrián Barbet, Alejandro Ferrero, Nahuel Ramayo entre otros. 


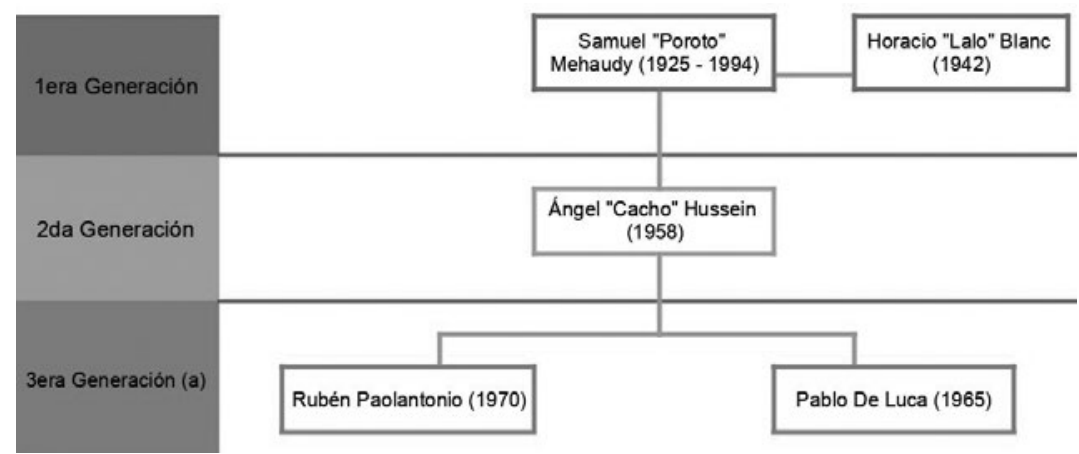

Figura I: Las primeras generaciones del recorrido histórico de la guitarra jazz en Santa Fe

Así, cada uno de estos actores recibió un legado y lo continuó: Mehaudy y Blanc fueron los primeros que mediante la curiosidad y el afán por tocar la guitarra desembocaron en la música de jazz. Ambos participaron de la escena musical del momento y plantaron la semilla que dio comienzo a todo. Posteriormente estos vínculos fueron tomados por Hussein, quien estableció los cimientos para comenzar el estudio general del jazz. A él se acercaron no solo guitarristas sino músicos de todos los instrumentos, ya que era una de las referencias más fuertes del género en la ciudad. "Cacho» fue el acceso al jazz para muchos de aquéllos jóvenes curiosos que no sabían por dónde empezar. Algunos de esos jóvenes fueron Paolantonio y De Luca, quienes pasaron por una etapa donde la tradición jazzística se estaba fusionando con una serie de diversos géneros y aproximándose a un sonido más eléctrico. Pablo desde un lado más «estilístico» adoptó aquel lenguaje y lo terminó de asimilar en Estados Unidos para luego enseñárselo a sus estudiantes en su retorno a Santa Fe. Por otro lado, Rubén aprovechó aquellas amalgamas musicales y decidió experimentar con ellas al mismo tiempo que se formó sólidamente como docente e intérprete del instrumento. 


\section{REFERENCIAS BIBLIOGRÁFICAS}

AYALA, CRISTÓBAL (2018): SECCION 06 V, Florida, Florida International University, pp.167. https://diazayalacollection.fiu.edu/sites/diazayalacollection.fiu.edu/files/ SECCIONO6V.pdf [Consultado el 01/01/2021].

BALZA, NANCY (2007): «Marianne: Cantante», en Diario El Litoral, Santa Fe, http://www.ellitoral.com/index.php/diarios/2007/09/01/nosotros/NOS-02.html

al día 13/09/2018 [Consultado el 13/08/2020]

BeCEyro, RAúl (2007): Jazz: Imágenes de Santa Fe II, Santa Fe, Taller de Cine de la UNL.

CASANOVAS, DARÍo EZequiel (2012): Santa Fe Jazz Ensamble: Hacia una descripción de su recorrido histórico, Santa Fe, Trabajo de Investigación para la materia Investigación Musicológica II del Instituto Superior de Música.

Castellano, oscar. Entrevista concedida a Ángel Hussein. Santa Fe, 20 de mayo de 2018; Virgínia Mehaudy. Santa Fe, 04 de noviembre de 2018; Muni Puyol. Santa Fe, 21 de mayo de 2018; Pablo De Luca. Santa Fe, 8 de junio de 2018; Pablo Somaglia. Santa Fe, 9 de septiembre de 2018; Pedro Casís. Santa Fe, 16 de septiembre de 2018; Roberto Maurer. Santa Fe, 9 de septiembre de 2018.

CORTI, BERENICE (2015): Jazz argentino. La música "negra” del país «blanco», Buenos Aires, Gourmet musical.

DESDE EL SAER. Entrevista concedida a Francisco Lo Vuolo. Santa Fe, 11 de agosto de 2010.

https://www.youtube.com/watch?v=2al4ZTu0cm4\&t=8s [Consultado el 13/08/2020].

el Litoral (2001): «Del Mismo Palo» en El Litoral. Santa Fe, https://www. ellitoral.com/index.php/diarios/2001/08/17/pantallayescenarios/PAN-02.html [Consultado el 14/08/2020]).

GIOIA, TED (1997): Historia del Jazz, Madrid, Turner-Fondo de Cultura Económica. GOldSACK, RAÚl (1995): La Batería. "Mis experiencias" La Docencia, Santa Fe, Edición independiente.

GOLDSACK, ELINA, LÓPEZ, MARÍA INÉS Y PÉREZ, HERNAN (2010) «La música de fusión en la ciudad de Santa Fe (Argentina) en la década del '80" en Asociación Internacional para el Estudio de la Música popular y Escuela Universitaria de Música: ¿Popular, pop, populachera? El dilema de las músicas populares en Amércia Latina, Caracas, pp. 212. http://www.ism.unl.edu.ar/ media/CAID/Goldsack\%20Lopez\%20y\%2OPerez.\%20La\%20musica\%20de\%20 fusion\%20en\%20la\%20ciudad\%20de\%20Santa\%20Fe.pdf [Consultado el 13/08/2020].

HERMANOS MAREA CORP (2002): Noches de jazz, producción independiente [DVD], Santa Fe. 
MAURER, ROBERTO (2008): "La lección del maestro", en El Litoral, Santa Fe, https://www.ellitoral.com/index.php/diarios/2008/10/25/nosotros/NOS-08.html [Consultado el 13/08/2020].

pÉreZ CHIARA, AMALIA MARTA (1973): La música en Santa Fe, Santa Fe, Gobierno de la provincia de Santa Fe.

POPSIKE.COM PIJUAN y su sexteto en el Tradewinds Borinquen https://www.popsike. com/PIJUAN-Y-SU-SEXTETO-EN-EL-TRADEWINDS-BORINQUEN-1039-1966ORIG-GREAT-HEAR/291651702847.html [Consultado el 01/01/2021].

PUjOL, SERGio (2004): Jazz al Sur, Buenos Aires, Emecé Argentina.

-(2015): Oscar Alemán. La guitarra embrujada, Buenos Aires, Planeta. SECRETARÍA DE CUltura de LA unL (2010): Apuntes de jazz \#1, (2010); \#2, (2011); \#3, (2012); \#4, (2013); \#5, (2014); \#6, (2015); \#7, (2016); \#8, (2017); Secretaría de Cultura de la Universidad Nacional del Litoral. SECretaría de Cultura de SANTA Fe (2009): Proyecto Aula-Ciudad / Fascículo NN 4. "Banda Municipal", Secretaría de Cultura de Santa Fe.

STEVens, KImberly (1997): "Clue to Global Warming: The Tango Is Coming Back», en The New York Times, New York, https://www.nytimes.com/1997/01/19/ nyregion/clue-to-global-warming-the-tango-is-coming-back.html [Consultado el 01/01/2021]. 